\title{
Fast through-bond diffusion of nitrogen in silicon
}

\author{
Peter A. Schultz and Jeffrey S. Nelson \\ Sandia National Laboratories, Albuquerque, NM 87185 \\ ( Received:

RECEIVED

AUG 172000

OSTI

We report first principles total energy calculations of interaction of nitrogen in silicon with silicon self-interstitials. Substitutional nitrogen captures a silicon interstitial with $3.5 \mathrm{eV}$ binding energy forming a $<001>$ split interstitial ground state geometry, with the nitrogen forming three bonds. The low energy migration path is through a bond bridge state having two bonds. Fast diffusion of nitrogen occurs through a pure interstitialcy mechanism: the nitrogen never has less than two bonds. Near-zero formation energy of the nitrogen interstitialcy with respect to the substitutional rationalizes the low solubility of substitutional nitrogen in silicon. 
Nitrogen implantation in silicon can be used to regulate gate oxide thickness, and enable the growth of ultra-thin gate oxides with improved uniformity in the oxide layer. ${ }^{1,2}$ Observed in this process is the complete removal of nitrogen from bulk $\mathrm{Si}$, and embedding of nitrogen at or near the $\mathrm{Si} / \mathrm{SiO}_{2}$ interface. ${ }^{3}$ In bulk $\mathrm{Si}$, nitrogen behaves markedly different from other group-V impurities. ${ }^{4}$ While $\mathrm{P}, \mathrm{As}, \mathrm{Sb}$, and $\mathrm{Bi}$ are shallow $n$-type dopants, occupying simple substitutional tetrahedral sites, substitutional nitrogen, $\mathrm{N}_{S}$, is a deep level impurity, trigonally distorted to form a defect with $\mathrm{C}_{3 \mathrm{v}}$ symmetry. ${ }^{5}$ Furthermore, the solubility of nitrogen in $\mathrm{Si}$ is very low, ${ }^{4-7}$ with less than $5 \%$ of implanted nitrogen being incorporated in SL5 centers corresponding to $\mathrm{N}_{s} .5$. A key element in both the bulk behavior of nitrogen and its effect on oxidation kinetics is rapid diffusion of nitrogen, to form silicon-nitride complexes, collect at other defects, or embed at the $\mathrm{Si} / \mathrm{SiO}_{2}$ interface. The purpose of this paper is to identify and understand the nature of this rapid diffusing nitrogen specie.

Diffusion of dopants and other impurities in bulk $\mathrm{Si}$ is frequently enhanced by interaction with self-interstitials, $\mathrm{Si}_{i}$, or vacancies. Copious numbers of these intrinsic defects are byproducts of the damage caused by implantation, and subsequent thermal annealing or other processing to heal this damage results in the enhanced diffusion of implanted impurities, altering dopant profiles and hampering efforts to reduce feature sizes in integrated circuits. Diffusion of antimony and other large dopant species is believed to be mediated predominantly by vacancies, while the diffusion of boron is mediated by self-interstitials. In previous work, ${ }^{8}$ substitutional nitrogen, unlike boron and carbon, was shown to strongly bind a Si vacancy. All these first row impurities, however, have large vacancy-exchange barriers, precluding facile diffusion mediated by vacancies, with the largest exchange barrier, $4.4 \mathrm{eV}$, being predicted for nitrogen. ${ }^{8}$ Calculations have verified an interstitialcy mechanism for boron diffusion, $, 9,10$ where boron migrates between substitutional sites via a hexagonal interstitial site. In this work we present results indicating that nitrogen, like boron, also diffuses as an interstitialcy. However, the formation energy of the $\mathrm{N}$ interstitialcy is near zero, in a $<100>$ split interstitial with three bonds. Furthermore, the migration 


\section{DISCLAIMER}

This report was prepared as an account of work sponsored by an agency of the United States Government. Neither the United States Government nor any agency thereof, nor any of their employees, make any warranty, express or implied, or assumes any legal liability or responsibility for the accuracy, completeness, or usefulness of any information, apparatus, product, or process disclosed, or represents that its use would not infringe privately owned rights. Reference herein to any specific commercial product, process, or service by trade name, trademark, manufacturer, or otherwise does not necessarily constitute or imply its endorsement, recommendation, or favoring by the United States Government or any agency thereof. The views and opinions of authors expressed herein do not necessarily state or reflect those of the United States Government or any agency thereof. 


\section{DISCLAIMER}

Portions of this document may be illegible in electronic image products. Images are produced from the best available original document. 
is via a through-bond path rather than through lattice interstices. Nitrogen never has fewer than two bonds to silicon atoms. The path through a bond-bridging interstitialcy has a small migration barrier. These results rationalize both the low solubility of $\mathrm{N}_{s}$ in $\mathrm{Si}$, and the rapid migration of implanted $\mathrm{N}$ to a nearby $\mathrm{Si} / \mathrm{SiO}_{2}$ interface.

The calculations use SEQQUEST, a gaussian-based linear combination of atomic orbitals (LCAO) method, 11 invoking the local density approximation (LDA) ${ }^{12}$ to density functional theory ${ }^{13}$ as parameterized by Perdew and Zunger. ${ }^{14}$ The standard non-local forms of normconserving pseudopotentials are used for nitrogen ${ }^{15}$ and silicon. ${ }^{16}$ High quality "double-zeta plus polarization" contracted gaussian basis sets ${ }^{17}$ are used on all atoms: two radial degrees of freedom for $s$ - and $p$-orbitals and a single gaussian $d$-function for angular polarization. Simulations of defect structure are accomplished via the supercell approximation, ${ }^{18,19}$ using 64 -site cubic cells with Brillioun zone sampling up to an equivalent of Monkhorst-Pack ${ }^{20}$ parameters of $(3,3,3)$ to check for sampling convergence, and 216-site cubic cells with up to $(2,2,2)$ sampling for selected defect structures to check convergence with cell size. Note the $64 /(3,3,3)$ cell and $216 /(2,2,2)$ cell have formally equivalent Brillioun zone sampling. This equivalence was verified computationally. The atoms were relaxed to equilibrium structures by eliminating forces using a modified Broyden method, ${ }^{21}$ in cell sizes fixed using the theoretical lattice parameter $(5.43 \AA)$.

A variety of structures were explored for the interaction of $\mathrm{N}_{s}$ and $\mathrm{Si}_{i}$, divisible into three classes: (1) non-bonded interstitial $\mathrm{N}, \mathrm{N}_{i}$, in a perturbed silicon lattice; (2) substitutional $\mathrm{N}$, with a non-bonded $\mathrm{Si}_{i}$ in a nearby interstice, $\mathrm{N}_{\mathcal{S}}-\mathrm{Si}_{i} ;$; 3 ) and fully bonded (NSi) interstitialcies.

The lowest energy structures all incorporate all atoms into the lattice, with the nitrogen atom having at least two bonds to neighboring silicon atoms. Furthermore, the potential energy surfaces explored by various relaxation paths are remarkably flat. The most stable structure is a $<100>$ split interstitial, where the nitrogen shares a lattice site with a silicon atom, and is bonded to a total of three silicon atoms, as depicted in Figure 1(a). The nitrogen forms a planar arrangement with its three silicon neighbors, in much the same arrangement as in crystalline $\mathrm{Si}_{3} \mathrm{~N}_{4}$. The lowest energy form of this defect actually buckles the $<100>$ split interstitial, reducing the defect symmetry from 
$\mathrm{C}_{2 \mathrm{v}}$ to $\mathrm{C}_{\mathrm{s}}$, as the $\mathrm{Si}$ which shares the lattice site with $\mathrm{N}$ weakly coordinates with a $\mathrm{Si}$ second nearest neighbor to the N, denoted by the dashed line in Figure 1(a), to form a four-member ring. This buckling is modest, however, resulting in less than $0.1 \mathrm{eV}$ energy lowering from the symmetric defect, and serves mainly to highlight the flat potential energy surface around this defect. It takes place in both the 64-site cell and 216-site cell, with approximately the same energetics, suggesting that the buckling is not related to stress.

The next highest energy configuration of the nitrogen interstitial, rather than as a non-bonded interstitial as found for boron, is a bond-bridge site, depicted in Figure 1(b). The bridge-bonded $\mathrm{N}$ is only $0.4 \mathrm{eV}$ higher in energy than the $<100>$ split-interstitial in the 64 -site cell, and $0.5 \mathrm{eV}$ higher in the 216-site cell. Strain does not seem to be critical in influencing the conformation of this defect. Again, the potential surface is remarkably flat. The barrier to rotation of the nitrogen atom around the $\mathrm{Si}-\mathrm{Si}$ bond axis is very small $(<0.1 \mathrm{eV})$, as, in fact, is the barrier through the bond $(\sim 0.1 \mathrm{eV})$, in a linear $\mathrm{Si}-\mathrm{N}-\mathrm{Si}$ configuration having $\mathrm{D}_{3 \mathrm{~d}}$ symmetry.

Non-bonded atoms incur a large energy cost for the nitrogen interstitial. The non-bonded $\mathrm{N}_{i}$ structures are universally unstable. A nitrogen atom in the high symmetry tetrahedral or hexagonal interstitial sites has zero forces, but these are maxima on the energy surface. A nitrogen atom placed elsewhere in the interstitial regions of the lattice inserts itself to bond into the surrounding lattice. Similarly, a non-bonded $\mathrm{Si}$ self-interstitial next to $\mathrm{N}_{S}$ inserts itself without barrier between the nitrogen and a neighboring silicon, unless constrained by symmetry.

A non-bonded nitrogen in a lattice interstice is at least $1.8 \mathrm{eV}$ higher in energy (in the hexagonal $\mathrm{C}_{3 \mathrm{v}}$ site), and inserts into the lattice, typically without an observed barrier. A substitutional $\mathrm{N}$ with a nearby non-bonded silicon interstitial is at least another $0.5 \mathrm{eV}$ higher yet (for $\mathrm{Si}_{i}-\mathrm{N}_{S}-\mathrm{Si}$ or $\mathrm{N}_{s}-\mathrm{Si}_{-}-\mathrm{Si}_{i}$ constrained to $\mathrm{C}_{3 \mathrm{v}}$ symmetry), or inserts between $\mathrm{N}_{s}$ and its nearest neighbor $\mathrm{Si}$ atoms in the lattice, from any interstitial position neighboring the nitrogen. This is in contrast to results obtained with boron, where the lowest energy configuration consists of a substitutional boron and $\mathrm{Si}_{i}$ in a nearest neighbor (approximately) tetrahedral site. ${ }^{22,9,10}$ The is a 
direct consequence of the $\mathrm{N}_{s}-\mathrm{Si}_{i}$ binding energy computed here being much higher than the binding energy of $\mathrm{B}_{s}-\mathrm{Si}_{i}$.

Substitutional nitrogen has a large computed binding energy with a silicon self-interstitial:

$$
\mathrm{N}_{s}+\mathrm{Si}_{i} \rightarrow \mathrm{NSi}_{<100>}+3.5 \mathrm{eV}
$$

This energy is comparable to the formation energy of the isolated Si self-interstitial in this calculation $(3.6 \mathrm{eV})$. Hence, the formation energy of the $\mathrm{N}$ interstitial with respect to the $\mathrm{Si}$ crystal is less than $0.1 \mathrm{eV}$, and the isolated substitutional nitrogen is only marginally thermodynamically stable in the lattice. This result of the current calculations is consistent with, and provides a physical explanation for, the low solubility of $\mathrm{N}_{S}$ in crystalline silicon.

The diffusion of nitrogen is facilitated in transient enhanced diffusion by silicon selfinterstitials. The bare substitutional nitrogen, or vacancy-nitrogen complex is immobile. Once the interstitial complex is formed, the migration of nitrogen through silicon proceeds from the threebonded $<100>$ split interstitial through the two-bonded bridge, only $0.4 \mathrm{eV}$ higher, and then to another adjacent split interstitial. The activation energy for diffusion is a sum of formation energy of the $\mathrm{N}_{\mathrm{s}}-\mathrm{Si}_{\mathrm{i}}$ complex, $<0.1 \mathrm{eV}$ from above, and the migration energy of the nitrogen through the lattice. Using as the barrier the $0.4 \mathrm{eV}$ at the bridge site, this yields an activation energy for interstitial mediated nitrogen diffusion of the lattice of $0.5 \mathrm{eV}$, a remarkably small value. Compare, for example, the experimental activation energies ${ }^{23}$ (interstitial plus vacancy) for boron, $3.5 \mathrm{eV}$, or for isoelectronic phosphorus, $3.6 \mathrm{eV}$. In an environment where Si self-interstitials are mobile, nitrogen will capture a passing interstitial, also become mobile, and diffuse very rapidly to some trapping site, such as a $\mathrm{Si} / \mathrm{SiO}_{2}$ interface. The high binding energy of the complex reduces the activation energy, and ensures that the nitrogen interstitialcy never dissociates into a silicon self-interstitial and an immobile nitrogen substitutional defect. The physical picture offered by these results directly accounts for the diffusive behavior described in a study of implanted nitrogen in silicon, ${ }^{24}$ and provides physical parameters that can be used in process model simulators. 
In summary, we have identified the nitrogen interstitial defect that is the rapidly diffusing specie in silicon. Nitrogen moves as through the crystal from a three-bonded split interstitial site to a two-bonded bridge site and back again, without any atom ever leaving the lattice to become unbonded. Despite a remarkably high binding energy of the nitrogen substitutional and the interstitial, this migration occurs with a low migration barrier energy. As a byproduct of this mechanism, we explain why substitutional nitrogen has such low solubility in silicon.

\section{Acknowledgments}

Sandia is a multiprogram laboratory operated by Sandia Corporation, a Lockheed Martin Company, for the United States Department of Energy, under Contract No. DEAC0494AL85000.

\section{References}

1 C.T. Liu, Y. Ma, J. Becerro, S. Nakahara, D.J. Eaglesham, and S.J. Hillenios, IEEE Electron Device Letters 18, 105 (1997).

2 C.T. Liu, E.J. Lloyd, Y. Ma, M. Du, R.L. Opila, and S.J. Hillenius, IEDM 95,19.2, p499502.

3 L.S. Adam, M.E. Law, O. Dokumaci, Y. Haddara, C. Murthy, H. Park, S. Hegde, D. Chidambarrao, S. Mollis, T. Domenicucci, C. Dziobkowski, K. Jones, P. Wong, R. Young, and R. Srinivasan, in Silicon Front--End Processing: Physics and Technology of Dopant-Defect Interactions, edited by H.-J. Gossman, T.E. Haynes, M.E. Law, A.N. Larsen, S. Odanaka, MRS Symposia Proceedings No. 568 (Materials Research Society, Warrendale PA, 1999), p. 277.

4 P.V. Pavlov, E.I. Zorin, D.I. Tetelbaum, and A.F. Khokhlov, Phys. Stat. Sol (a). 35, 11 (1976).

5 K.L. Brower, Phys. Rev. Lett. 44, 1627 (1980); Phys. Rev. B 26, 6040 (1980).

6 W. Kaiser and C.D. Thurmond, J. App. Phys. 30, 247 (1959). 
7 J.B. Mitchell, P.P. Pronko, J. Shewchun, D.A. Thompson, and J.A. Davies, J. App. Phys. 46, 332 (1975).

8 J.S. Nelson, P.A. Schultz, and A.F. Wright, App. Phys. Lett. 73, 247 (1998).

9 B. Sadigh, T.J. Lenosky, S.K. Theiss, M.-J. Caturla, T. Diaz de la Rubia, and M.A. Foad, Phys. Rev. Lett 83, 4341 (1999).

10 W. Windl, M.M. Bunea, R. Stumpf, S.T. Dunham, and M.P. Masquelier, Phys. Rev. Lett 83, 4345 (1999).

11 P.A. Schultz and P.J. Feibelman, unpublished; for a description of the method see: P.J. Feibelman, Phys. Rev. B 35, 2626 (1987).

12 W. Kohn and L.J. Sham, Phys. Rev. 140, A1133 (1965); see also Theory of the Inhomogeneous Electron Gas, edited by S. Lundqvist and N.M. March (Plenum, New York, 1983).

13 J. Perdew and A. Zunger, Phys. Rev. B 23, 5048 (1981).

14 P. Hohenberg and W. Kohn, Phys. Rev. 136, B864 (1964).

15 N. Troullier and J.L. Martins, Phys. Rev. B 43, 8861 (1991).

16 D.R. Hamann, Phys. Rev. B 40, 2980 (1989).

17 P.A. Schultz, unpublished.

18 R.P. Messmer, B. McCarroll and C.M. Singal, J. Vac. Sci. Technol. 9, 891 (1972); G.D. Watkins and R.P. Messmer, in Computational Methods for Large Molecules and Localized States in Solids, edited by F. Herman, A.D. McLean, and R.K. Nesbet, Plenum Press (New York, 1973) p. 133; R.P. Messmer and G.D. Watkins, in Radiation Damage and Defects in Semiconductors, Conference Series No. 16, The Institute of Physics, (London, 1973), p. 255.

19 M.L. Cohen, M. Schlüter, J.R. Chelikowsky, and S.G. Louie, Phys. Rev. B 12, 5575 (1975).

${ }^{20}$ H.J. Monkhorst and J.D. Pack, Phys. Rev. B 13, 5188 (1976).

21 D.D. Johnson, Phys. Rev. B 38, 12807 (1988). 
22 J. Zhu, T. Diaz de la Rubia, L.H. Yang, C. Mailhoit, and G.H. Gilmer, Phys. Rev. B 54, 4741 (1996).

23 P.M. Fahey, P.B. Griffith, and J.D. Plummer, Rev. Mod. Phys. 61, 289 (1989), and references therein.

24 L.S. Adam, M.E. Law, K.S. Jones, O. Dokumaci, C.S. Murthy, and S. Hegde, J. Appl. Phys. 872282 (2000). 


\section{Figure Captions.}

Figure 1. Schematics of the low-energy structures for interstitial nitrogen. The open circle represents the position of the nitrogen atom, the dark circles the positions of nearby silicon atoms.

(a) The ground state configuration: the $<100>$ split interstitial with nitrogen having a bond to each of three neighboring silicon atoms. The dashed line represents the weakly coordinated silicon atoms that approach each other to reduce the symmetry from $\mathrm{C}_{3 \mathrm{v}}$ to $\mathrm{C}_{\mathrm{s}}$. (b) The bond bridge site, $0.4 \mathrm{eV}$ higher in energy. The nitrogen diffuses from split interstitial to bridge to next split interstitial. 


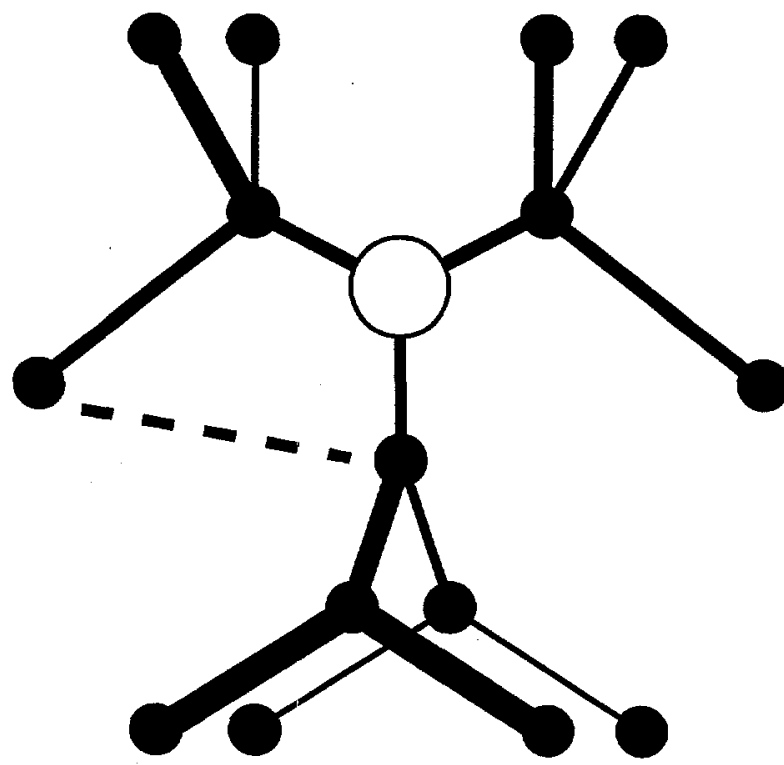

(a)

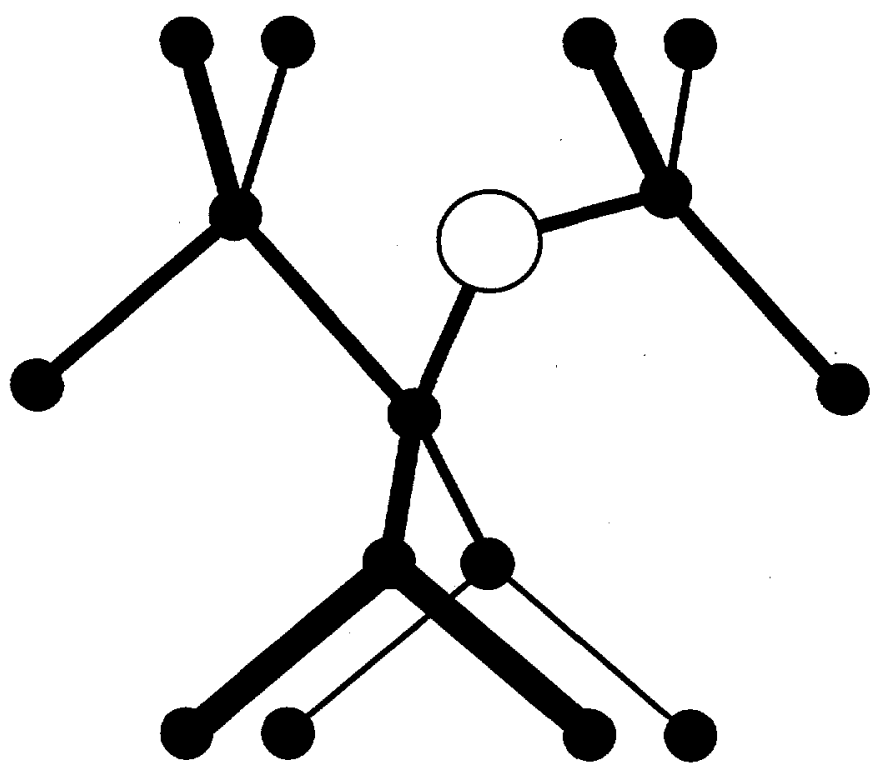

(b)

Schultz and Nelson, Figure 1 